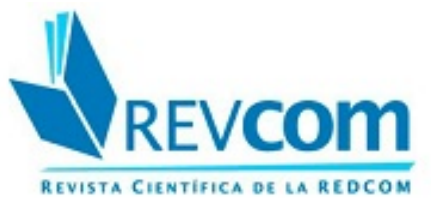

REVCOM. Revista científica de la red de carreras de Comunicación Social

ISSN: 2451-7836

redcom.revcom@gmail.com

Universidad Nacional de La Plata

Argentina

\title{
La otredad en la extimidad
}

Odetti, Verónica Beatriz

La otredad en la extimidad

REVCOM. Revista científica de la red de carreras de Comunicación Social, núm. 10, 2020

Universidad Nacional de La Plata, Argentina

DOI: https://doi.org/10.24215/24517836e037 


\title{
La otredad en la extimidad
}

\author{
A alteridade no extimidade \\ The otherness in extimity \\ Verónica Beatriz Odetti \\ Universidad Nacional de Entre Rios, Argentina \\ veronicaodetti013@gmail.com
}

DOI: https://doi.org/10.24215/24517836e037

Recepción: 30 Marzo 2020

Aprobación: 09 Junio 2020

\section{Resumen:}

El presente artículo busca destejer las nuevas configuraciones de la subjetividad en el contexto de la extimidad (Sibilia, 2008), es decir, pensar reflexivamente estos nuevos modos de ser y estar en las redes, poniendo especial atención a la configuración de las subjetividades desde la alteridad. Para tal fin se tensionan las propuestas teóricas de Lévinas, Maturana y Sibilia. Emerge entonces una nueva gestión del yo en sus coordenadas espaciales y temporales signadas por la virtualidad y las redes sociales, donde el rostro (Lévinas, 1987) y la legitimidad del otro (Maturana, 1997) adquieren presencia en un like o emojis o stikers. No hay rostro ni emociones que permitan configurar la alteridad, aparecen caricaturas que remedan emociones y que buscan suplir ese lugar del otro en la configuración de las subjetividades instantáneas, instagrameables y fugaces que se nos presentan.

Palabras clave: Otredad, subjetividad, extimidad, emociones.

\section{Resumo:}

Este artigo busca desvendar as novas configurações de subjetividade no contexto da extimidade (Sibilia, 2008), ou seja, pensar reflexivamente sobre essas novas formas de ser e de estar em rede, prestando atenção especial à configuração das subjetividades a partir da alteridade, para as quais são enfatizadas as propostas teóricas de Lévinas, Maturana e Sibilia. Em seguida, emerge uma nova gestão do eu em suas coordenadas espaciais e temporais marcadas pela virtualidade e pelas redes sociais, onde o rosto (Lévinas, 1987) e a legitimidade do outro (Maturana, 1997) ganham presença em um like ou emoji ou stikers. Não existem rostos ou emoções que nos permitam configurar a alteridade, aparecem desenhos que imitam emoções e que buscam substituir esse lugar pelo outro na configuração das subjetividades instantâneas, instagramáveis e fugazes que nos são apresentadas.

PALAVRAS-CHAVE: alteridade, subjetividade, extimidade, emoções.

\section{Abstract:}

The present article intends to unravel the new configurations of subjectivity in the context of extimity (Sibilia, 2008), as in reflexively thinking about these new forms of being and appearing online, putting special focus in the configuration of the subjectivity that comes from alterity. To that end, we put the theoretical proposals of Lévinas, Maturana and Sibilia in tension. A new management of the self in its spatial-temporal coordinates then emerges, engraved in virtuallity and social media, where the face (Lévinas, 1987) and the legitimacy of the other (Maturana, 1997) acquire presence in the form of a like or emojis and stikers. There is no face nor emotions that could allow to configure alterity, caricatures appear, which mimic emotions and seek to replace the place of the other configuration of the subjectivity, that becomes instant, instagrammable and fleeting.

KEYWORDS: Otherness, subjectivity, extimity, emotions.

\section{INTRODUCCIÓN}

Nos encontramos ante un contexto que podemos describir como de hiper- complejidad (Morin, 1999), es decir, entendiendo por complejo del latín complectere, cuya raíz plectere significa trenzar, enlazar, y el prefijo "com" añade el sentido de la dualidad de dos elementos opuestos que se enlazan íntimamente, pero sin anular su dualidad, aquello que se encuentra trenzado, enlazado junto; y el prefijo hiper que significa exceso, 
superioridad y que pretende denotar la profundización de ese tejido conjunto. Todo intento de focalización puede entenderse como un recorte y en muchos casos hasta como un reduccionismo simplista.

Siguiendo esta descripción, hoy podemos afirmar que vivimos en una Sociedad Red, caracterizada por el desarrollo de redes de información que procesan, almacenan y transmiten esta sin restricciones de distancia, tiempo ni volumen. Esta red de redes nos presenta una malla, un tejido que entrelaza, siguiendo a Thomas Hughes (2008), las definiciones de la sociedad y la tecnología. Es decir, un complejo entramado donde tecnología, ciencia, sociedad se entremezclan y se entrelazan y resulta prácticamente imposible separar productos o relaciones exclusivamente sociales o exclusivamente tecnológicos, lo que nos permite afirmar que los conceptos de tecnología y sociedad no son aislables o estancos, sino que por lo contrario se presentan como una compleja red donde el desarrollo social configura y es configurado por la tecnología, en una relación bidireccional. Hughes descarta la reducción del término tecnología a artefactos físicos y prefiere hablar de tecnología como sistemas tecnológicos o sociotécnicos. En esta Sociedad Red, entendemos que la estructura social está construida en torno a redes de información a partir de la tecnología de información microelectrónica estructurada en Internet.

A partir de lo expresado comprendemos a las redes sociales - Facebook, Instagram, Twitter, entre otrasen tanto sitios de internet formados por un conjunto de personas que tienen intereses compartidos, sea por temas de entretenimiento, diversión, comerciales, amistad, trabajo, parentesco, etc.; y que en los últimos años han adquirido una relevancia cada vez mayor en nuestra cotidianidad. Estas redes sociales permiten el contacto entre los miembros de su comunidad, con diversos objetivos que van desde comunicarse e intercambiar información, a mostrarse, publicitarse y publicitar productos, marcas y servicios. Quienes participan de estas redes sociales, no necesariamente deben conocerse previamente, sino todo lo contrario ya que generalmente el primer contacto se da través de la misma y sin llegar a la presencialidad. Resulta pertinente destacar que mediante estas redes sociales los usuarios crean perfiles donde representan una versión de sí mismos que utilizan para interactuar y compartir con otros.

En esta nueva era de incertidumbres, resulta necesario comprender los flujos de las nuevas prácticas, teorías, narraciones, instituciones que surgen día a día transformando nuestra manera de aprender, de relacionarnos, de comunicarnos, de comprar y vender, de amar y sufrir, de crear y producir. Las redes sociales se inscriben como una parte fundamental de la interacción de millones de personas, deviniendo en nuevas formas de comunicación interpersonal, que impactan en el lenguaje, en la socialización, en las formas de identificarse y representarse a sí mismos, en los modos de ser y estar.

Teniendo en cuenta la descripción efectuada, y en el marco de respetar la complejidad sin dejar de reconocer las limitaciones propias que la temática presenta, resulta pertinente preguntar, indagar y reflexionar sobre el otro, sobre la alteridad, principalmente porque nos encontramos en tiempos signados por la extimidad (Sibilia;2008) donde la espectacularidad del yo invade todos los espacios virtuales, quedando sujeto a la mirada del otro. A una mirada reducida a aprobar o desaprobar, una mirada contemplativa de la construcción de ese yo extimio que solamente adquiere relevancia en cuanto a la demanda de popularidad, de aprobación, de aceptación. Estas características nos llevan a preguntarnos qué espacio queda para la otredad en esa configuración del yo, qué lugar ocupa la configuración del alter en la subjetividad contemporánea.

Para poder permitirnos pensar estos nuevos modos de ser y estar en las redes poniendo especial atención a la configuración de las subjetividades desde la alteridad, nos proponemos tensionar los abordajes teóricos de Lévinas, Maturana y Sibilia, en el intento de bosquejar los trazos de un recorrido que entendemos no presenta un punto de llegada, que se encuentra en mutación permanente y que la velocidad de las nuevas tecnologías en cuanto a la incorporación constante de nuevos dispositivos así como también la celeridad que imprimen el envío de datos, la incorporación permanente de nuevos contactos y configuraciones de redes de redes, que en determinados momentos puede leerse como rapidez y en otros como fugacidad, constituye el desafío a enfrentar sin perder el eje primario. 


\section{LAS NUEVAS CONFIGURACIONES DE LA OTREDAD-SUBJETIVIDAD}

En primer lugar, resulta relevante destacar que no existe un único modo de concebir la otredad, puesto que la compresión e interpretación del término está en conexión con las diferentes corrientes teóricas de cada época. La noción de otredad proviene de una categoría antropológica que se presenta como habitual en filosofía, sociología, antropología y otras ciencias y nos permite pensar el otro como alguien que me interpela, me indaga, me cuestiona. En resumidas palabras podemos decir que se trata del reconocimiento del otro como un individuo diferente, otro que se constituye para poder constituirme yo.

Tomando la propuesta del filósofo Emmanuel Lévinas, discípulo de Edmund Husserl, la presencia de un otro, de lo diferente, lo ajeno, lo extraño, aquello que deviene en lo que no soy pero sin embargo necesito para poder constituir mi yo soy. Esa concepción del otro que deviene rostro y tensiona mi responsabilidad, mi identidad, surge de la construcción teórica de Lévinas (1991) que percibe al otro como aquello que no puede objetivarse, un infinito donde reconocerse o asimilarse en el encuentro cara a cara, yendo hacia él, encontrándose con él, volviéndolo rostro, "nosotros llamamos rostro al modo en el cuál se presenta el otro, que supera la idea del otro en mi” (Lévinas, 1987, p. 208).

Lévinas adopta la responsabilidad o ética del rostro, donde el otro es rostro que me concierne, que establece significación, sentido. El autor describe el «recibimiento del rostro», dado cuenta que la relación con un «rostro» no puede reducirse a la dinámica de la visión, o como se mencionó, objetivación. "El rostro; su revelación es palabra. Sólo la relación con otro... nos conduce hacia una relación totalmente diferente de la experiencia en el sentido sensible del término". (Lévinas, 1987, p. 207).

Toda relación para con un rostro estará siempre condenada a ser ética, ya sea para bien o para mal. El autor define al rostro en forma negativa, "El rostro está presente en su negación a ser contenido. En este sentido no podría ser comprendido, es decir, englobado. Ni visto ni tocado” (Lévinas, 1987, p. 207).

El rosto desborda el significado de las partes: frente, nariz, boca.... así como el conjunto de las mismas, es la potencia expresiva que determina toda relación y la expresividad del lenguaje le otorga el abordaje positivo del concepto, es decir, la fuerza significativa y de interpelación que el rostro conlleva.

...el «rostro» es el origen de todo sentido y discurso, ahora debemos añadir que este sentido y discurso es la responsabilidad que suscita el otro de cara al yo. Finalmente, del «cara-a-cara» se deriva una responsabilidad al margen de la autonomía del sujeto, un compromiso ético anterior a la decisión y acción del sujeto (Navarro 2008, p.184)

Hoy la pretensión de ese "cara a cara" se encuentra mediatizado por las tecnologías y resulta significativo poder pensar como en estas nuevas formas de relacionarnos con el otro, con los otros se mediatiza. Y si bien podemos pensar que ciertos encuentros pueden adquirir presencia mediantes los vivos, las video llamadas, etc. ese "cara a cara" se ha metamorfoseado en "imagen a imagen". El rostro del otro es la imagen del otro y nos atrevemos a aseverar que esa imagen retocada, mejorada, desdibuja la idea ética del encuentro con el otro cayendo en una mirada moralizante y principalmente señaladora, que indica qué mirar.

En tanto la aceptación de otro como un otro legítimo que formula el biólogo chileno Humberto Maturana (1997) está ligada a la posibilidad de pensar la otredad desde el amor, desde un lugar donde las emociones reemplazan al rostro.

El amor es el dominio de aquellas conductas relacionales a través de las cuales otro surge como otro legítimo en coexistencia con uno mismo bajo cualquier circunstancia. El amor no legitima a otro, el amor deja tranquilo al otro aunque viéndolo e implica actuar con él de un modo que no necesita justificar su existencia en la relación. (Maturana, 1997, p. 45)

Maturana define al amor desde su perspectiva como biólogo y considera que es la emoción fundamental que hace posible nuestra evolución como seres humanos en tanto seres autopoiéticos en acople estructural con su medio. Refiere al amor no en tanto sentimiento ni referido a la bondad o sugiriendo generosidad, sino que cuando habla de amor lo hace entendiéndolo como un fenómeno biológico, es decir, la emoción que especifica el dominio de acciones en las cuales los sistemas vivientes coordinan sus acciones de forma tal que 
devenga la aceptación mutua. El amor es entonces, la emoción que configura el dominio de acciones en que nuestras interacciones recurrentes con el otro hacen que ese otro sea un legítimo otro en la convivencia.

La palabra emoción proviene del latín emotǐo, que significa "movimiento o impulso", "aquello que te mueve hacia", el impulso que mueve a la acción. Maturana (1997) afirma que todo sistema racional tiene un fundamento emocionaly, por tanto, cuando nos encontramos en una emoción, hay ciertas cosas que podemos hacer y otras que no, y ciertos argumentos que aceptamos como válidos y otros que no.

Desde el punto de vista biológico lo que connotamos cuando hablamos de emociones son disposiciones corporales dinámicas que definen los distintos dominios de acción en los que nos movemos. Cuando uno cambia de emoción, cambia de dominio de acción. (Maturana, 1997, p.15)

Las emociones hacen referencia al dominio de acciones posibles del otro y a las disposiciones corporales que las constituyen y habilitan, "no hay acción humana sin una emoción que la funde como tal y la haga posible como acto” (Maturana, 1997, p.723). Las emociones no son censurables, no se pueden controlar, lo que podemos hacer es tomar conciencia de su accionar, dado que son disposiciones corporales dinámicas que habilitan diferentes dominios de acción, es decir, hacen referencia al dominio de acciones posibles del otro y a las disposiciones corporales que las constituyen y habilitan. Al hablar de mis emociones cambio de emoción y las convierto en sentimientos, en operaciones de operaciones. Las emociones nos permiten observar los dominios de acción posibles -agredir, alabar, aceptar, golpear, pegar-y las disposiciones corporales del otro tono de voz, postura, ritmo, movimientos, palabras, silencios- y detectar en qué emoción se encuentra -alegría, tristeza, enojo, miedo, amor- para abordar lo que está ocurriendo como una totalidad.

La otredad adquiere significación en la respuesta de otro: el accionar, el moverse, el expresarse, el emocionar del otro, otorga significado a mí moverme, expresarme, emocionarme, el otro me permite significarme. La presencia del otro, de la alteridad surge desde las emociones, en tanto el otro emerge en una dinámica emocional, que lo reconoce, lo legitima o lo descalifica, lo ataca. Desde la emociones nos permitimos pensar la otredad. Las emociones hacen referencia al dominio de acciones posibles del otro (Maturana, 1997) y a las disposiciones corporales que las constituyen y habilitan, cuando uno cambia de emoción, cambia de dominio de acción. Cuando estas emociones tienen lugar en la virtualidad o mediadas por las tecnologías en muchos casos surge la confusión, no es posible identificar la emoción o se entiende que la emoción es otra, producto de la aparición de los emoticones. Este término es el plural del vocablo inglés emoticón, que deriva de las palabras emotion -emoción- e icon -icono-. Los emoticones son dibujos de caras humanas, hechas con puntos, guiones, y otros símbolos gráficos que se utilizan en las redes sociales a fin de representar estados de ánimo. La Real Academia Española (RAE) lo incluye como emoticono y lo define como "la representación de una expresión facial que se utiliza en mensajes electrónicos para aludir al estado de ánimo del remitente”. Estos emoticonos fueron utilizados por primera vez en 1982 por un profesor universitario y constan de símbolos que requieren se gire la cabeza $90^{\circ}$, en el caso occidental, para comprender su significado. Estos emoticonos dieron paso a los ya populares emoji, según el término japonés, o emoticono gráfico, podríamos decir. Los emojis convirtieron esos símbolos en imágenes de $12 \times 12$ pixeles y tuvieron sus inicios en la década del noventa en Japón, con el objetivo de facilitar y agilizar la comunicación digital. Actualmente son muy utilizados para comunicarse a través de la mensajería digital y están presentes en diversas apps como WhatsApp, o Hangouts y principalmente en las redes sociales como Facebook, Twitter o Instagram. Los usos de estos pictogramas comenzaron a popularizarse rápidamente de forma tal que sus antecesores cayeron en el olvido. Se estima que existen aproximadamente unos 1500 emojis y la cifra continúa en aumento año a año, esto llevo a que se propongan diccionarios y manuales que dicten el uso adecuado de los mismos.

Estas imágenes devienen en la búsqueda de expresar emociones o en estados emocionales, y cuando nos referimos a los estados emocionales estamos haciendo mención a la duración de una emoción. Los emoticonos y los emojis se presentan como el remedo de las emociones que vivenciamos pero que nos resulta dificultoso expresar en las redes sociales respetando la velocidad de los intercambios, donde la celeridad del 
tipeo dictamina el tipo de encuentro y la complejidad de cada emoción se cierne a una carita que difiere de significado según la comunidad, el contexto y los usuarios.

Mencionamos previamente que la otredad adquiere significación en la respuesta del otro, pero actualmente observamos que esta significación se virtualiza y debido a la complejidad de significados que postulan los emojis, establecer el dominio de acciones se torna confuso y en numerosos casos demanda de una explicación.

Siguiendo la propuesta de Lévinas y Maturana podemos observar que esa búsqueda de la aceptación del otro, de los otros, de ser tenido en cuenta, de ser aceptado, de ser reconocido, de constituirse como un otro legítimo, digno de reconocimiento y de hablar y ser escuchado, de aparecer como un rostro legítimo, desde una responsabilidad ética pareciera desdibujarse en las redes sociales donde se presentan nuevos modos-configuraciones tensionados por la instantaneidad, mercantilización y calificación-descalificación moralizante.

Observamos que las nuevas tecnologías como expresa Sibilia (2008) nos proponen otros modos de ser y de leer el yo, es decir, una nueva gestión del yo en sus coordenadas espaciales y temporales signadas por la virtualidad y las redes sociales, donde el rostro que formula Lévinas adquiere presencia en un like o algunos emojis, o algún stiker. El rostro se caricaturiza en consonancia con la propia imagen photoshopeada, donde el privilegio de la "exhibición total" no solamente vacía de contenidos, sino que desdibuja la otredad y, por ende, el yo. No hay rostro ni emociones, desde la conceptualización que proponen Lévinas y Maturana, que permitan configurar la alteridad, aparecen caricaturas que remedan emociones y que buscan suplir ese lugar del otro en la configuración de las subjetividades instantáneas, instagrameables y fugaces que se nos presentan. La instantaneidad refiere a esta exigencia de velocidad -fugacidad que imprimen las redes sociales, el encuentro con el otro se encuentra mediado por las tecnologías y en esa mediación el rostro y las emociones se metamorfosean por las condiciones propias de dicho encuentro con la otredad y por ende con uno mismo.

La configuración de la subjetividad ha entrado en mutación, Sibilia (2008) al respecto expresa que, en muchos sentidos, estaríamos ante una transición, dejando de ser ese sujeto moderno y nos estaríamos transformando en otra cosa. En este proceso distingue las opresiones de la modernidad de las que nos hemos liberado y nos invita a indagar estas rupturas, a observar qué nuevas opresiones nos proponen estas mutaciones. A partir de lo cual podemos referir que el sujeto moderno se centraba en torno a la noción de esencia del ser, el no cambio, la estabilidad, se formulaban como el imperativo social, el no fingir, el sujeto debía serse fiel toda su vida, no había espacio para la simulación. En tanto, hoy en día, el imperativo consiste en lo contrario, el continuo reciclado de uno mismo, el hacer referencia constantemente al "estar siendo", la exigencia de reinventarse, de reformular la manera en la que queremos ser, entendiendo que queremos ser visibles, exponernos constantemente.

Resulta oportuno preguntarse cómo estos nuevos modos de configurar la alteridad en las redes sociales anudan el yo, no a rostros no ni a emociones sino a la caricaturización. Y principalmente cómo estos modos devienen en vínculos dependientes de la aceptación no de otro sino de muchos otros, de un alter que carece de rostro, de una masa de otros donde se deposita el peso de la popularidad, del reconocimiento, y en alguna medida, la configuración de la subjetividad. En cierto nivel la autora señala esta presencia del otro, su rol y sus alcances.

De modo que son los otros, definidos de modo creciente como espectadores o seguidores, quienes tienen la capacidad de decir quién es cada uno y cuánto vale, incluso de un modo muy literal: haciendo clic en el botón "me gusta" o bien despreciando sus manifestaciones visibles. Es así como se le concede (o no) la misma existencia al yo que se expone, algo pasible de ser evaluado mediante la constante medición de visualizaciones, comentarios y repercusiones. (Sibilia, 2017)

En el marco de vivir expuesto, de mostrarse permanentemente ante la mirada del otro que refiere Sibilia, esta se presenta como una mirada moral que inmediatamente cuando descalifica o desprecia las publicaciones no deviene en vergüenza sino en la constitución del otro en tanto enemigo. Ese rostro maléfico que debe eliminarse y por ende es inmediatamente bloqueado o suprimido de la lista de contactos, por ejemplo. 
Esta mirada no logra configurarse como un rostro que mira, dado que solamente juzga, solo se presenta como aval para dar prestigio o quitarlo, no es una mirada que ve, que observa, que otorga identidad, aquella mirada moderna, sino que es una mirada contemporánea que en cierta medida adquiere las características propias de un programa, que toma ciertos parámetros y valora por sí o por no sin dimensionar las repercusiones que esto genere. Una mirada que pierde esa razón del ser propia de la modernidad y que se presenta con una característica ligada al juicio, a imprimir una valoración sobre el otro.

Lévinas sostiene que reconocer al otro implica una responsabilidad ética, donde ese extraño puede volver un rostro fraterno pero que como ya hemos mencionado se trunca dado que no logra el encuentro con ese rostro, sino que se topa con la imagen que ha elegido el otro para presentarse. La responsabilidad ética que esa otredad formula se desvanece ante la valoración moralista.

Siguiendo lo expresado nos encontramos con ese otro que se nos presenta desde la apariencia y plantea el desafío de pensar esa imagen como una mercancía, un producto comerciable, una marca personal que demanda cuidado, dedicación.

Porque la imagen de cada uno deviene su propia marca, un capital tan valioso que es necesario cuidarlo y cultivarlo, con el fin de encarnar un personaje atrayente en el competitivo mercado de las miradas. Para lograrlo, el catálogo de tácticas mediáticas y de marketing personal a nuestra disposición es, hoy en día, increíblemente vasto, y no deja de ampliarse y renovarse sin cesar. (Sibilia 2008, p. 292)

El otro-rostro devenido en imagen-marca personal que debe producirse para esos nuevos mercados donde la apariencia es la influencer - la referencia al termino influencer proviene del uso que adquiere en las redes sociales, es decir, una persona que tiene presencia y credibilidad en las mismas contando con un número elevado de seguidores, es quien influye, viraliza contenidos, crea historias, incide a partir de su comportamiento virtual - por excelencia, no permite espacio para la ética o las emociones, solo aparece el remedo de esa alteridad caricaturizada y nos convoca a preguntarnos por estos nuevos modos de configurar la otredad y como se juega esa configuración de la subjetividad contemporánea, que necesita exhibirse.

Porque se trata de un tipo de yo que se construye en la visibilidad, tanto en la exposición de su vida supuestamente privada como de su personalidad, y que se propone como un estilo o una actitud a ser imitada, con el fin de acercarse al atrayente campo magnético de las celebridades (Sibilia 2008, p.284)

Se invitó a un grupo de 82 estudiantes, asistentes a las Segundas Jornadas de Psicología Social: Vínculos, subjetividades y redes, organizada por la cátedra Psicología Social perteneciente a las Carreras Licenciatura en Psicología y Profesorado en Psicología de la Facultad de Humanidades, Artes y Ciencias Sociales de Universidad Autónoma de Entre Ríos, a realizar un sencillo ejercicio, con el objetivo de observar la configuración de la subjetividad tensionada por la presencialidad-virtualidad que cotidianamente vivencian. Se les solicito que constituyan aleatoriamente parejas y posteriormente se pidió que cada uno tome su móvil y elija una foto del perfil de cualquier aplicación que utilice con mayor frecuencia y se la muestre a su par.

Inmediatamente apareció el extrañamiento, la incomodidad y la molestia que se hicieron presente en risas, sonrisas y movimientos corporales de distanciamiento, que seguidamente fueron ratificadas en los comentarios expresados verbalmente por algunos asistentes que eligieron aleatoriamente tomar la palabra: "fue incomodo, mostrar mi perfil y mi rostro", "uno se ríe porque se siente molesto, incómodo" " ser visto en el perfil cara a cara me resulta raro", "inmediatamente me aleje, es raro, no por ver al otro sino porque el otro me ve a mí"

La vivencia de enfrentar ese encuentro con el otro, pantalla a pantalla y cara a cara, puso en tensión en el aquí, ahora conmigo, el encuentro de las configuraciones de la subjetividad, habilitando la reflexión colectiva sobre los modos de ser y estar que se tejen en nuestro hacer cotidiano desde la presencialidadvirtualidad. El otro virtual y el otro presencial se presentan, como rara vez ocurre, en un mismo espacio y en un mismo tiempo, es decir, una espacio temporalidad que ordena de manera ubicua cuasi instantánea y fugaz el encuentro tradicional con ese rostro que me mira. 
Esta síntesis entrama ambos modos de configurar al otro, aquel que cuyo rostro- emociones me interpelan y demandan una responsabilidad ética, y aquél que se caricaturiza, se muestra, se vende y reclama una valoración moral. Se tejen juntos y se metamorfosean en una nueva configuración de la subjetividad tironeada por los modos de ser y estar de la presencialidad y la virtualidad, con los modos de convivir que tienen lugar, con los haceres que cotidianamente se despliegan.

Pareciera que estas miradas que se nos presentan como dicotómicas, disociadas, donde no tienen nada que ver una y la otra, que dan cuenta de modos disjuntos, que en un recorrido veloz aparecerían como incompatibles, se encuentran dispuestas a conversar y lo que es aún más movilizante están conversando, negociando, debatiendo, configurando nuevos modos de ser y estar que convergen los anteriores, y ese desafío nos convoca a continuar investigando estos procesos.

\section{Conclusión}

Ante este yo que se construye en la espectacularización, su par contrapuesto, el alter, también sigue sus pasos, entonces pasamos de la tensión entre un yo-alter que se configuraba desde un rostro con mirada ética amorosa, a un yo-alter que acontece en las pantallas, un rostro-imagen moralizante que demanda todo el tiempo la banalización de las miradas aprobadoras o descalificadoras. Esto conlleva la pérdida de contenido, o bien podríamos atrevernos a suponer que el contenido que se pierde refiere a otra época, y que lo que nos resulta disruptivo radica en que no podemos comprender ese nuevo contenido que estas nuevas configuraciones de la otredad nos plantean y nos demandan.

Las mutaciones que se han generado en estos complejos contextos actuales demandan, sin lugar a dudas, espacios de conversaciones, reflexiones y análisis no para encontrar ni la respuesta, ni las respuestas, sino para continuar tejiendo las redes que nos habiliten a comprender estas nuevas configuraciones contemporáneas y su entramado con las subjetividades modernas puesto que, tal como se describió con anterioridad, conviven y se disputan permanentemente en nuestros haceres cotidianos. Esta confluencia de ser y estar modernas y contemporáneas nos llevan a reflexionar. El concepto de reflexión etimológicamente deviene del latín reflectus, flectus significa "acción de doblar o curvar", y el prefijo re significa, de nuevo, hacia atrás. Por lo cual la propuesta implica volvernos sobre estas subjetividades modernas y contemporáneas permitiéndonos revisar cómo se entretejen y permiten la emergencia de estas nuevas configuraciones.

Tomando al escritor Octavio Paz (1993), y su conceptualización poética de la otredad, entendida como un sentimiento de extrañeza que indefectiblemente algún punto de nuestras vidas nos pone en tensión nuestra propia individualidad, podemos pensar la otredad como el extrañamiento en tanto necesidad y demanda de reconocerme, de reconocer mi individualidad. Observamos que debemos profundizar cómo estos nuevos sujetos se extrañan, como ya no es posible pensar este extrañamiento por fuera de las redes sino en ese complexus donde se encuentra tejido, junto. Indagar estos rostros-imágenes de múltiples remedos emocionales y observar cómo se producen, circulan y consumen estas nuevas subjetividades.

La otredad, las formas de percibir, de configurar al otro y por consecuencia de configurar, construir mi identidad han mutado y como hemos expresado encuentran nuevos modos de emerger y desplegarse en las redes, en las pantallas, en la virtualidad y en la cotidianidad. Resulta significativo observar que no solamente se pone el foco en esas mutaciones sino en la velocidad y cambio que las caracteriza en tanto fenómeno en movimiento, es decir, la incorporación permanente de nuevos dispositivos, tecnologías y la aceleración en tanto duración del estar, de lo que está siendo y de lo que es, la fugacidad. Frente a lo cual nos preguntamos ¿se conserva algo en estos procesos?, ¿qué se está conservando y qué no? La velocidad de las redes, de la web, torna fugaces cada modo de ser y estar y configura inmediatamente nuevos modos, habilitando nuevos espacios para la reflexión y para la indagación, pero esa velocidad impacta profundamente en los procesos de subjetivación. 


\section{REFERENCIAS}

Lévinas, E. (1987). Totalidad e Infinito. Ensayo sobre la exterioridad. Salamanca, España: Ediciones Sígueme.

Lévinas, E. (1991). Ética e infinito. Madrid, España: A. Machado Libros.

Maturana, H. (1997). Emociones y Lenguaje en Educación y Política. Chile: Granica.

Morin, E. (1999). Los 7 saberes necesarios para la educación del futuro. París, Francia: UNESCO.

Navarro, O. (2008). El «rostro» del otro: Una lectura de la ética de la alteridad de Emmanuel Lévinas. Contrastes. Revista Internacional de Filosofia, vol. XIII, 177-194.

Paz, O. (1993). Itinerario. México: Fondo de Cultura Económica.

Sibilia, P. (2008). La intimidad como espectáculo. Buenos Aires: Fondo de Cultura Económica.

Sibilia, P. (5 de agosto de 2017). Bullying: La vergüenza. Revista Anfibia. Recuperado de http://revistaanfibia.com/e nsayo/la-verguenza/ 